\title{
Exciting times for regional scientists
}

\author{
Peter Batey ${ }^{1}$
}

(C) The Japan Section of the Regional Science Association International 2017

The launch of a new journal is surely an occasion for celebration. It marks an important stage in the growth of an academic organisation, one that provides an opportunity to record for posterity progress that has been made in the development of theories, methods and applications. Unlike a conference paper, which may have been produced quickly and presented briefly to what can often be quite a small audience, a journal paper is invariably carefully crafted and intended to be read by many over a substantial period of time. It will usually have benefited from a process of refinement as an author seeks to reflect the comments and suggestions of referees and editors.

To a new author, publication in a journal can be seen as a landmark, a point at which their research has achieved national, and possibly international, recognition. A good journal will make a point of helping such authors in their quest for publication, appreciating the importance of the journal as a forum for new ideas and fresh thinking. Journal editors have an exciting, but challenging, task in choosing what and who to publish, to develop over time a new journal's reputation and style, its 'personality' if you like. This is all the more important in an inter-disciplinary field like regional science where we have such a lot to learn from each other.

As regional scientists, we are fortunate in having a worldwide network of fellow scholars and researchers. Over the last 60 years the Regional Science Association International (RSAI) has grown from its roots in North America to become a thriving organisation with strong hubs in Europe and the Pacific. As a European, my first links as a young academic were with the British Section of the RSAI: indeed my first published paper appeared in that Section's journal, London Papers in

P. Batey: Past-President of the Regional Science Association International.

Peter Batey

pwjbatey@liverpool.ac.uk

1 University of Liverpool, Liverpool, UK 
Regional Science. Soon I was able to attend European regional science meetings, as my personal academic network extended. And later, as an editor of what was to become Papers in Regional Science, I became much more conscious of research that was going on beyond my immediate field of interest.

I particulary value the academic links I developed with regional scientists in the Asia-Pacific region. More often than not, it was a discussion at a PRSCO meeting that helped me take the next step in my research and it was gratifying to find fellow academics who were wrestling with precisely the same academic problems. More recently, it has been extremely rewarding to supervise a large number of graduate students from throughout the Asia-Pacific region and to appreciate the similarities and differences of the regions we all study.

I regard the launch of the Asia-Pacific Journal of Regional Science as a timely and very welcome development in the worldwide 'family' of regional science. 